\title{
Function Area Defining of Freeway Ramp
}

\author{
Shipeng Zhao,a, Qiaojun Xiang ${ }^{1, b}$ \\ ${ }^{1}$ Transportation College,Southeast University,Nanjing 210096,China. \\ azhaoshipengy@126.com, bxj@seu.edu.cn
}

Key words: Freeway; Ramp; Functional area; Traffic state

Abstract:Based on existing research and standards ,this paper proposed a new method of freeway ramp function area calculation, divided the ramp into upstream function area, downstream function area and ramp function area, and redefined each function area. Moreover, according to the relationship among vehicle speed of certain point, the time required to change lanes, design speed and other parameters,modified the time of a lane change in the "Traffic Engineering Handbook", proposed new equation of each area and figure out the length.

\section{Introduction}

Statistics show that China's freeway mileage in total road is less than $2 \%$, while the number of accidents, deaths and the proportion of direct losses accounted for $4.55 \%, 10.34 \%$ and $31.97 \%$ of all accidents respectively ${ }^{[1-3]}$. freeway accident with feature of major traffic accidents, high casualty rate, far-reaching impact and direct serious economic losses etc., has become an important factor restricting the sustainable development of freeway transportation.

With the number growth of freeway and improving of freeway network, as a link with the outside world, driving status of freeway ramp function area will have an increasingly important impact on the efficiency of the freeway network.

For a long time researchers divided the ramp into weaving area, merging area and diversion area on the basis of morphological structures freeway ramp and it's geometric characteristics, This approach is not reasonable, freeway ramp as an organic whole,should combine with changes of traffic flow characteristics, give a reasonable definition from functional perspective research on entrance ramp.

\section{Freeway ramp function area}

Due to exist of exit ramp, main line traffic merge and split, traffic flow is disturbed. Traffic flow and vehicle type will be re-distribution after re-select of driveway. the vehicle from the main driveway is limited by the exit ramp linear, need adjust the speed constantly to suit the split; while import vehicles from the main ramp restricted by linear ramp, need adjust the speed constantly to join the main line. For the above reasons, the exit ramp upstream and entrance ramp downstream areas are traffic disorder with complex vehicles types, different driving behavior, make it a high incidence of traffic accidents region and main point of freeway design and research. This paper based on survey data, combined with existing standards and research on ramp, re-defines the function area of exit ramp.

Freeway exit ramp function area composition as shown in Fig. 1, includes three parts, upstream function area, downstream function area and ramp function area. 


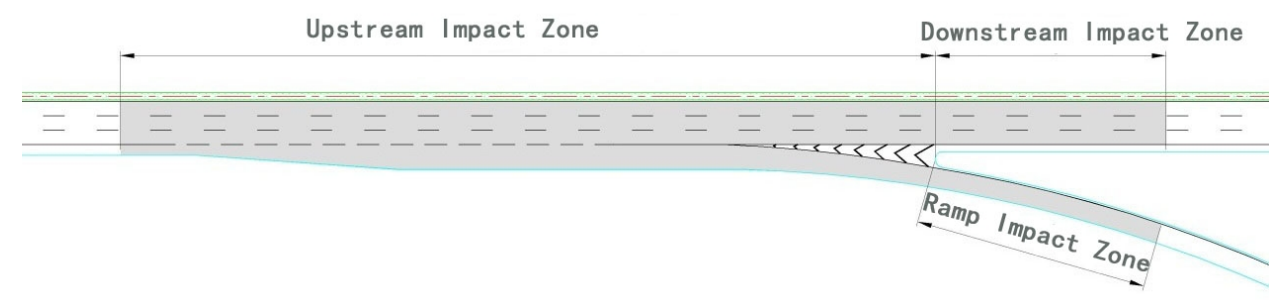

Fig. 1 Freeway exit ramp function area

(1) Upstream of the function area

In the upstream area, generally inside driveway driver begin to change driveways to the outside after they discovery of the exit ramp signs or directly identify exit, to prepare for enter the deceleration driveway. When traveling to near the starting point of deceleration driveway, drivers begin to decelerate speed and search space for insert, when there is proper clearance, the vehicle accelerated into the outermost driveway; after driving some distance, transformed into the deceleration driveway or with other vehicles leave exit ramp.

This paper defined upstream function area from the freeway facilities to meet the space requirement of Split-flowing vehicle, ensure traffic safety. Upstream function area should contains two parts, one is traveling vehicle distance while Split-flowing at the entrance $L_{s}$ or sight judgment distance $L_{e}$, the former reflects the range of vehicles affected by Split-flowing, while the latter is based on the safety and security design parameters, both have to be considered, take bigger value in calculation while two distance conflict; the other part is the length of the deceleration driveway. Upstream of the exit ramp function area length is calculated as Equation 1.

$$
L_{u}=\max \left(L_{\varepsilon}, L_{s}\right)+L_{d e c e l}
$$

Where:

$L_{u^{-}}$length of exit ramp upstream function area, m;

$L_{e^{--}}$exit sight judge distance, $\mathrm{m}$;

$L_{\mathrm{S}}{ }^{--}$exit sign visual distance, $\mathrm{m}$;

$L_{\text {decel }}{ }^{--}$deceleration driveway length, $\mathrm{m}$.

1) Exit sight judge distance

Sight judge distance (also called identification sight distance) is the safety distance for driver noticed the complex information and judge the situation is proper to drive .

China's "Traffic Engineering Handbook" ${ }^{[7]}$ point out: the sight distance for vehicle drive out of exit ramp not only meet the requirement of parking but also need to meet the requirement of vehicle safely and smoothly pulled out of the main line, until drivers recognize the transition section of the traffic situation, changing driveway and the entire tapered end on ramp triangle. So exit sight judge distance at least 1.25 times of parking distance. Exit sight judge distance as shown in Table 1.

Table 1 China "traffic engineering manual" sight judge distance recommended value

\begin{tabular}{|c|c|c|c|c|c|}
\hline Design speed $(\mathrm{km} / \mathrm{h})$ & 120 & 100 & 80 & 60 & 40 \\
\hline Recognition distance $(\mathrm{m})$ & $350 \sim 460$ & $290 \sim 380$ & $230 \sim 300$ & $170 \sim 240$ & $130 \sim 180$ \\
\hline
\end{tabular}

The sight judge distance suggested in the United States "green book" ,as shown in Table 2.

Table 2 United States "green book" sight judge distance recommended value

\begin{tabular}{|c|c|c|c|c|c|c|c|c|c|}
\hline Design speed $(\mathrm{km} / \mathrm{h})$ & 130 & 120 & 110 & 100 & 90 & 80 & 70 & 60 & 50 \\
\hline Recognition distance $(\mathrm{m})$ & 390 & 360 & 330 & 315 & 270 & 230 & 200 & 170 & 145 \\
\hline
\end{tabular}


As can be seen from the comparison of Table 1 and Table 2, the two countries do not contradict, since the "Green Paper" give recommendation of sight distance calculations, help for determine the scope of the function area, the paper take this recommended value in the US "Green Book" .

2) Sign visibility distance

China's "Road traffic signs and markings - Part II: Road traffic signs" (GB 5768.2-2009) stipulates the noticed sign. When the freeway, A road ,B road or city fast highway as the crossed road, noticed sign should be separately set before the exit ramp from the based point $2 \mathrm{~km}, 1 \mathrm{~km}$, $500 \mathrm{~m}$, based point can be starting point of gradual deceleration driveway segment.

The driver's identification information and knowledge processes can generally be divided into discover, recognize, read, understand, act and disappear.

Exit ramp sign visibility distance is calculated as shown in Equation 2, where the parameter chosen from China's "Traffic Engineering Manual" recommendations.

$$
d=d_{p}+d_{\mathrm{il}}+d_{\mathrm{a}}-d_{0} \geq v_{1} t_{1}+v_{2} t_{2}+(n-1) v_{1} t_{3}+\frac{1}{2 \pi}\left(v_{1}^{2}-v_{2}^{2}\right)
$$

Where:

$d$-- exit ramp sign visual distance, $\mathrm{m}$;

$d_{r^{-}}$recognize signs distance, $\mathrm{m}$;

$d_{d^{-}}$judging sign distance, $\mathrm{m}$;

$d_{a^{--}}$action distance, $\mathrm{m}$;

$d_{0^{--}}$sign pre-distance, because the sign is set at the starting point here, so is 0 ;

$v_{1^{--}}$speed of vehicle when sign found at the exit ramp, $\mathrm{m} / \mathrm{s}$, preferable $85 \%$ of the vehicle driving speed;

$v_{2^{--}}$arrives at the beginning of the deceleration driveway speed, $\mathrm{m} / \mathrm{s}$;

$t_{1--}$ time required to recognize and read signs, s, usually $1 \sim 2 \mathrm{~s}$;

$t_{2--}$ time determine measures to be taken, s, usually $2.0 \sim 2.5 \mathrm{~s}$;

$t_{3^{--}}$time required to change driveways one time, s, generally the $10 \mathrm{~s}$;

$n$-- way main line driveways, one direction;

$a$-- deceleration speed, $\mathrm{m} / \mathrm{s}^{2}$, generally take $0.75 \sim 1.5 \mathrm{~m} / \mathrm{s}^{2}$.

In the equation 2 it has been considered with the length for a series of processes from signs visible to driveway. In addition, according to "Traffic Engineering Handbook", for one-way 2-driveway freeway and more driveways freeway, 10s for change driveway is too long, the paper modified this parameter $t_{3}$. According to research, the vehicle traveling at high speed, the driver need $4 \mathrm{~s}$ to find a gap space, about $3 \sim 4$ s to traverse a driveway, so it's usually up to about 8 s that a driveway change can be completed. Therefore, this paper modified Equation 3 based on the assumes that the driver find a space can be inserted and immediately change driveway. as amended, see Equation 3. $t_{4}$ is the time for vehicle is traversing a driveway. The remaining parameters defined as Equation 2.

$$
d=v_{1} t_{1}+v_{2} t_{2}+\left[4+(n-1) t_{4}\right] v_{1}+\frac{1}{2 a}\left(v_{1}^{3}-v_{2}^{3}\right)
$$

Among them, $V_{1}$ and $V_{2}$ obtained through field investigation, used Bushnell hand-held radar gun research on diverse small passenger cars at the point of Nanjing-Hefei freeway, Yangzhou-Liyang freeway, Nanjing-Hangzhou freeway and Shanghai-Nanjing freeway, for the reason of small buses can be used as standard cars. Measurements include two parts, one is small passenger vehicle speed on main line, the other is vehicle speed at Split-flow point. In order to 
minimize the impact of vehicle Split-flowing, the speed measurement point set at about $1000 \mathrm{~m}$ from starting of deceleration driveway. Specific data see Table 3 and Table 4.

Table 3 Speed of vehicle on main line freeway

\begin{tabular}{|c|c|c|c|c|c|c|c|c|c|}
\hline Sample point & $\begin{array}{c}\text { NJ-HF } \\
\text { A }\end{array}$ & $\begin{array}{c}\text { NJ-HF } \\
\text { B }\end{array}$ & $\begin{array}{c}\text { NJ-HF } \\
\text { C }\end{array}$ & $\begin{array}{c}\text { NJ-HF } \\
\text { D }\end{array}$ & $\begin{array}{c}\text { YZ-LY } \\
\text { A }\end{array}$ & $\begin{array}{c}\text { YZ-LY } \\
\text { B }\end{array}$ & $\begin{array}{c}\text { NJ-HZ } \\
\text { A }\end{array}$ & $\begin{array}{c}\text { NJ-HZ } \\
\text { B }\end{array}$ & $\begin{array}{c}\text { SH } \\
\text {-NJ }\end{array}$ \\
\hline Design speed $(\mathrm{km} / \mathrm{h})$ & 100 & 100 & 100 & 100 & 100 & 100 & 120 & 120 & 120 \\
\hline Average speed $(\mathrm{km} / \mathrm{h})$ & 79.5 & 85.7 & 83.4 & 72.5 & 76.5 & 77.7 & 94.8 & 91.6 & $\begin{array}{c}93 . \\
2\end{array}$ \\
\hline $85 \%$ uniform speed $(\mathrm{km} / \mathrm{h})$ & 92.3 & 99.6 & 96 & 84 & 90 & 92 & 111.1 & 106.9 & 109 \\
\hline
\end{tabular}

Table 4 speed of vehicle at starting point on exit freeway ramp

\begin{tabular}{|c|c|c|c|c|c|c|c|c|c|}
\hline Sample point & $\begin{array}{c}\text { NJ-HF } \\
\text { A }\end{array}$ & $\begin{array}{c}\text { NJ-HF } \\
\text { B }\end{array}$ & $\begin{array}{c}\text { NJ-HF } \\
\text { C }\end{array}$ & $\begin{array}{c}\text { NJ-HF } \\
\text { D }\end{array}$ & $\begin{array}{c}\text { YZ-LY } \\
\text { A }\end{array}$ & $\begin{array}{c}\text { YZ-LY } \\
\text { B }\end{array}$ & $\begin{array}{c}\text { NJ-HZ } \\
\text { A }\end{array}$ & $\begin{array}{c}\text { NJ-HZ } \\
\text { B }\end{array}$ & SH-NJ \\
\hline Design speed $(\mathrm{km} / \mathrm{h})$ & 100 & 100 & 100 & 100 & 100 & 100 & 120 & 120 & 120 \\
\hline Average speed $(\mathrm{km} / \mathrm{h})$ & 73.6 & 78.6 & 77.2 & 68.4 & 70.6 & 75.3 & 87 & 84.6 & 85.7 \\
\hline
\end{tabular}

By field measurements, it was found that there is a relationship among speed at exit ramp visible sign $V_{l}$, speed at the starting point on the deceleration driveway $V_{2}$ and design speed, as shown in Equation 4 and Equation 5.

$$
V_{1}=\frac{V_{d}-10}{3.6}
$$

Where:

$V_{l^{-}}$speed at ramp exit signs, $\mathrm{m} / \mathrm{s}$;

$V_{d^{-}}$freeway design speed, $\mathrm{km} / \mathrm{h}$;

$$
V_{2}=\frac{V_{d}-V_{m}}{3.6}
$$

Where:

$V_{2^{--}}$speed at the beginning of the deceleration driveway, $\mathrm{m} / \mathrm{s}$;

$V_{d^{-}}$- freeway design speed, $\mathrm{km} / \mathrm{h}$;

$V_{m^{-}}$freeway speed parameter, $\mathrm{km} / \mathrm{h}$.

Freeway speed parameter $V_{m}$ in Equation 5 shown in Table 5, for the case of unable to measurement $V_{m}$ can be get from interpolation method or adjust the value appropriate to the actual situation, this paper choose interpolation method .

Table 5 Freeway speed parameter $V_{m}$

\begin{tabular}{|c|c|c|c|}
\hline Design speed $(\mathrm{km} / \mathrm{h})$ & 120 & 100 & 80 \\
\hline $\mathrm{V}_{\mathrm{m}}$ & 35 & 25 & 15 \\
\hline
\end{tabular}

Combining with Equation 3, Equation 4 and Equation 5, the sign visibility distance can be calculated at starting of deceleration driveway on freeway exit ramp, as shown in Table 6(where $t_{1}$ takes $1 \mathrm{~s}, t_{2}$ takes $2 \mathrm{~s}, t_{4}$ takes $3 \mathrm{~s}$, a takes $1.2 \mathrm{~m} / \mathrm{s}^{2}$ ). 
Table 6 The sign visibility distance at starting of deceleration driveway on freeway exit ramp

\begin{tabular}{|c|c|c|c|c|c|c|c|}
\hline One way lane number & \multicolumn{3}{|c|}{2} & \multicolumn{3}{|c|}{3} & 4 \\
\hline Main line design speed $(\mathrm{km} / \mathrm{h})$ & 120 & 100 & 80 & 120 & 100 & 80 & 120 \\
\hline Sign visible distance $(\mathrm{m})$ & 390 & 270 & 175 & 420 & 300 & 195 & 450 \\
\hline
\end{tabular}

3) The length of the deceleration driveway

This paper object is the freeway that has been completed and put into use, so the length of the deceleration driveway took from "Road Design Specification" (JTG D20-2006), as shown in Table 7.

Table 7 The length of the deceleration driveway

\begin{tabular}{|c|c|c|c|}
\hline $\begin{array}{c}\text { Main line design speed } \\
(\mathrm{km} / \mathrm{h})\end{array}$ & $\begin{array}{c}\text { Deceleration driveway } \\
\text { length }(\mathrm{m})\end{array}$ & $\begin{array}{c}\text { gradual change road } \\
\text { length }(\mathrm{m})\end{array}$ & $\begin{array}{c}\text { length of the deceleration } \\
\text { driveway }(\mathrm{m})\end{array}$ \\
\hline 120 & 145 & 100 & 245 \\
\hline 100 & 125 & 90 & 190 \\
\hline 80 & 110 & 80 & 215 \\
\hline
\end{tabular}

From research, the freeway exit ramp upstream area length can be got, as shown in Table 8.

Table 8 Freeway exit ramp upstream area

\begin{tabular}{|c|c|c|c|}
\hline $\begin{array}{c}\text { Design speed } \\
(\mathrm{km} / \mathrm{h})\end{array}$ & Max $\left(L_{e}, L_{s}\right)(\mathrm{m})$ & $\begin{array}{c}\text { Deceleration driveway length } \\
(\mathrm{m})\end{array}$ & $\begin{array}{c}\text { Entrance ramp upstream function } \\
\text { length }(\mathrm{m})\end{array}$ \\
\hline 120 & 450 & 245 & 695 \\
\hline 100 & 320 & 215 & 535 \\
\hline 80 & 220 & 190 & 410 \\
\hline
\end{tabular}

(2) Downstream function area

Downstream of the exit ramp function area is the vehicle distance from ramp triangle beginning to recover normal driving point. Taking into account that the performance of trailer is worse than car, take longer time and need longer distance to recover normal driving. This paper set trailer as study models. Researched on average speed of trailer at exit ramp triangle beginning on main line from Nanjing-Hefei freeway, Nanjing-Hangzhou freeway and other freeways, got the result as shown in Table 9.

Table 9 main line average speed and ramp triangle beginning average speed measurement result

\begin{tabular}{|c|c|c|c|c|c|c|c|c|c|}
\hline Sample point & $\begin{array}{c}\text { NJ-HF } \\
\text { A }\end{array}$ & $\begin{array}{c}\text { NJ-HF } \\
\text { B }\end{array}$ & $\begin{array}{c}\text { NJ-HF } \\
\text { C }\end{array}$ & $\begin{array}{c}\text { NJ-HF } \\
\text { D }\end{array}$ & $\begin{array}{c}\text { YZ-LY } \\
\text { A }\end{array}$ & $\begin{array}{c}\text { YZ-LY } \\
\text { B }\end{array}$ & $\begin{array}{c}\text { NJ-HZ } \\
\text { A }\end{array}$ & $\begin{array}{c}\text { NJ-HZ } \\
\text { B }\end{array}$ & SH-NJ \\
\hline $\begin{array}{c}\text { Split-flow point } \\
\text { average speed }\end{array}$ & 70 & 68.6 & 65.2 & 67.4 & 66.6 & 67.3 & 62 & 63.6 & 63.7 \\
\hline $\begin{array}{c}\text { main line average } \\
\text { speed }\end{array}$ & 73.6 & 72.6 & 67.2 & 73.2 & 68.5 & 72.4 & 71.5 & 67.3 & 68.4 \\
\hline
\end{tabular}

The measured data as seen in the Table 9, the exit ramp did influence vehicle traveling on the main line, trailer average speed at the ramp triangle beginning were lower than normal driving speed on the main line, but the difference is small, this indicated that the the vehicle can relatively rapid returned to normal driving after passing through the branch point. It is assumed that the vehicle is uniformly accelerated motion in the downstream area, the samples downstream length can got from Equation 6 . 


$$
L_{d}=\frac{v_{w a r}^{2}-v_{m m}^{2}}{25.92 a}
$$

Where:

$\mathrm{L}_{\mathrm{d}^{--}}$exit ramp downstream function area length, $\mathrm{m}$;

$\mathrm{V}_{\text {nor-- }}$ trailer on main line normal driving speed, $\mathrm{km} / \mathrm{h}$;

$\mathrm{V}_{\mathrm{mn}}$-- trailer an average speed at exit ramp triangle beginning, $\mathrm{km} / \mathrm{h}$;

$a$--deceleration, take AASHTO recommendation lower limit value $1 \mathrm{~m} / \mathrm{s}^{2}$,

This paper take the average length of downstream calculated by same design speed as the design speed of the function area length, then got different exit ramp downstream length of different design speed on main line, as shown in Table 10.

Table 10 Length of freeway exit ramp downstream area

\begin{tabular}{|c|c|c|c|}
\hline Main line design speed $(\mathrm{km} / \mathrm{h})$ & 120 & 100 & 80 \\
\hline length of freeway exit ramp downstream area $(\mathrm{m})$ & 40 & 30 & 20 \\
\hline
\end{tabular}

(3) Freeway ramp function area

Vehicles entering the exit ramp from main freeway, the driver of the vehicle had not get rid of the main fast-moving high-speed sense (with inertia), there would be a sustained deceleration, and then continued to accelerate drive out of ramp after a period of constant speed (before arriving at the toll booths). This paper thought the freeway ramp function area is the distance from Split-flow point to entering the main line, from continued decelerate speed to constant speed driving distance.

To calculate the function area, the paper selected four ramp sub-sections to measure small vehicle speed, the results are shown in Table 11.

Table 11 Different freeway ramp sub-section speed measurement

\begin{tabular}{|c|c|c|c|c|c|c|c|c|c|c|c|c|c|}
\hline \multicolumn{2}{|l|}{ Design speed $(\mathrm{km} / \mathrm{h})$} & 120 & 80 & 80 & 120 & 80 & 80 & 120 & 80 & 80 & 80 & 120 & 120 \\
\hline \multirow{6}{*}{$\begin{array}{l}\text { M easurement speed } \\
\text { of instrument layout point } \\
\qquad(\mathrm{km} / \mathrm{h})\end{array}$} & 1 & 75 & 72 & 70 & 72 & 69 & 76 & 70 & 71 & 76 & 77 & 69 & 71 \\
\hline & 2 & 68 & 56 & 65 & 68 & 62 & 64 & 65 & 61 & 64 & 73 & 72 & 70 \\
\hline & 3 & 71 & 55 & 61 & 66 & 60 & 61 & 61 & 56 & 61 & 67 & 68 & 66 \\
\hline & 4 & 63 & 55 & 58 & 65 & 58 & 66 & 58 & 61 & 66 & 63 & 65 & 61 \\
\hline & 5 & 57 & 64 & 59 & 67 & 65 & 64 & 59 & 69 & 64 & 64 & 64 & 62 \\
\hline & 6 & 61 & 75 & 72 & 66 & 70 & 77 & 72 & - & 71 & 64 & 63 & 59 \\
\hline
\end{tabular}

As the date shown above, it is obviously that the vehicle enter the exit ramp slow down first, accelerated to uniform speed second, re-accelereted at last. Without consider geometric linear ramp influence, assumed the vehicle pass the exit ramp Split-flow point from uniform deceleration to uniform driving , the travel distance can be calculated by Equation 7.

$$
L_{r}=\frac{v_{r r i d}^{2}-v_{a v p}^{2}}{25.92 a}
$$

Where:

$L_{r^{-}}$- exit ramp upstream function length, m;

$V_{\text {rnd }}$ - average speed of small car through Split-flow ramp point, $\mathrm{km} / \mathrm{h}$; 
$V_{a v e}$-- average speed of small car through entering ramp reach uniform driving, $\mathrm{km} / \mathrm{h}$;

$a$-- deceleration of small car on the ramp, take AASHTO recommendation value $1.2 \mathrm{~m} / \mathrm{s}^{2}$.

For average speed $V_{\text {ave }}$ which Split-flow small car from entering ramp to reach the uniform speed can approximate use the minimum speed value instead; for average speed $V_{\text {rnd }}$ which small car through ramp triangle area can use number in Table 11 point 1 of the instrument layout. Different driving speed length on main line can be calculated from Equation 7 , in order to ensure the effectiveness of functional areas, took the maximum as the length of exit ramp ramp function area ,as shown in Table 12.

Table 12 length of exit freeway ramp function area

\begin{tabular}{|c|c|c|c|}
\hline Main line design speed $(\mathrm{km} / \mathrm{h})$ & 120 & 100 & 80 \\
\hline Length of freeway ramp function area $(\mathrm{m})$ & 80 & 75 & 70 \\
\hline
\end{tabular}

\section{Conclusions}

This paper took account of the freeway traffic flow features and characteristics of the driver's driving behavior,proposed the calculation methods of freeway ramp function areas, combined with concrete case to specifically explain.

The definition of freeway ramp function area further clarify the main point of traffic safety improvement of freeway, has some significance in indicating freeway ramp traffic safety design.

\section{References}

[1] nearly five freeway accidents analysis [J] Traffic Management 2008 (05): 26-27.In Chinese

[2] Jian-Jun Cao. China freeway traffic accident analysis and countermeasures [J] Chinese transportation of .2013 (09): 121-124.In Chinese.

[3] Liu Dong, Ma Sheqiang,etc.China freeway traffic accident characteristic analysis [J], Chinese People's Public Security University (Natural Sciences) (2008) (4): 65-68.In Chinese.

[4] Ministry of Transportation freeway Research Institute. (GB5768-2009.2) road traffic signs and markings - Part 2: Road traffic sign [S]. Beijing: China Communication Press 2009.In Chinese.

[5] First freeway Survey Design and Research Institute (JTG D20-2006) freeway route design specifications [S]. Beijing: China Communications Press, 2006.In Chinese.

[6] CAO Hehong. Research on highway interchange speed change lane [D] Beijing: Beijing University of Technology, 1999.In Chinese.

[7] China highway society.Traffic engineering manual [R] Beijing: China Communications Press, 1997.In Chinese.

[8] Ministry of Transport of the People's Republic of China. (JTG D82-2009) freeway traffic signs and markings set specification [S] Beijing: China Communications Press ,2009.In Chinese.

[9] Ministry of Transportation freeway Research Institute. (JTG H20-2007) freeway technical condition assessment standards [S] Beijing: China Communications Press ,2008.In Chinese.

[10] Department of Highway Science Research Institute. (JTG H20-2007) Highway technical condition evaluation standard[S]. BeiJing: People's Communications Press, 2008.In Chinese.

[11] Buruya A. Speed-accident relationships on different kinds of European roads[R]. London: Transportation Research Laboratory. 1998. 
[12] M C Taylor, A Baruya and J V Kennedy. The relationship between speed and accidents of rural single-carriageway raod[R]. TRL Report 511. 2004.

[13] J. Wu, M. McDonald, K. Chatterjee. "A detailed evaluation of ramp metering impacts on driver behaviour". Transportation Research Part F 10 (2007) 61-75. 